6 Abstract

7

\title{
Dynamic and structural performances of offshore floating wind turbines in
} turbulent wind flow

\author{
Liang $\mathrm{Li}^{1}$, Yuanchuan $\mathrm{Liu}^{2,1}$, Zhiming Yuan ${ }^{1, *}$, Yan Gao ${ }^{1}$ \\ ${ }^{1}$ Department of Naval Architecture, Ocean and Marine Engineering, University of Strathclyde, UK \\ ${ }^{2}$ College of Engineering, Ocean University of China, China
}

A realistic turbulent wind field differs from a steady uniform one, in terms of the wind shear, the turbulence intensity and the coherence structure. Although it has been clear that an offshore floating wind turbine will behave differently in the turbulent wind, the individual effect of the above three items are not investigated sufficiently until now. The primary objective of the present research is to investigate in details how the wind shear, the turbulence intensity and the coherence influence the dynamic and structural responses of offshore floating wind turbines. Aero-hydro-servo-elastic coupled simulation of a semi-submersible floating wind turbine is run in time-domain. The wind shear has a limited effect on the global responses of the floating wind turbine although its influence on each individual blade is considerable. Comparatively, the floating wind turbine is quite sensitive to the turbulence intensity. In a wind field with high turbulence intensity, the platform motions become more violent and the structural loads are increased substantially. The proper orthogonal decomposition method is used to investigate the coherence quantitatively. A partial coherence structure helps to reduce the flow variation seen by the rotor and thereby beneficial to the safety of the floating wind turbine.

Keywords: turbulent wind; wind shear; turbulence intensity; coherence; offshore floating wind turbine; dynamic response; structural response

\section{Introduction}

Currently, great efforts are made around the world to pursue alternative energy sources, which are expected to be clean, sustainable and economic-efficient. Among various renewable energy resources, the application of wind energy has been proved successful, and the industry is trying to move to deep water zone to exploit the offshore wind energy. Since the proposal of the Hywind concept (Equinor, 2017a), the world's first full-scale offshore floating wind turbine, a set of floating wind turbine concepts have been proposed. Most recently, Hywind Scotland, the world's first floating wind farm, already starts to deliver electricity to the grid (Equinor, 2017b).

The model test has been accepted as a reliable approach to study the performances of offshore floating wind turbines. Duan et al. (2016) launched a model test program to investigate the vortex

* Corresponding author. Department of Naval Architecture, Ocean \& Marine Engineering, University of Strathclyde. E-mail address: zhiming.yuan@ strath.ac.uk (Z.M. Yuan). 
induced motion of a spar-type floating wind turbine. Li et al. (2018b) measured the dynamic response of a semisubmersible floating wind turbine in experimental environment, and a free-rotation method was proposed to correct the Reynolds number dissimilitude. Oguz et al. (2018) investigated the dynamics of a TLP floating wind turbine with both numerical and experimental methods. Apart from model test research, numerical simulation technology is also widely adopted by many researchers. Liu et al. (2017) developed an OpenFOAM-based simulation tool for the fully coupled model of floating wind turbines. The dynamic response and extreme structural response of an integrated floating turbine were investigated numerically in ( $\mathrm{Li}$ et al., 2018a; Li et al., 2018c). Their integrated concept was based on the combination of a floating wind turbine, two tidal turbines and a wave energy converter.

So far, the uniform wind flow is commonly adopted in both numerical and experimental studies of offshore wind turbines, which could simplify the aerodynamic modelling. Nevertheless, the wind field in the natural world is turbulent rather than uniform. A realistic wind field varies with not only time, but also space. Actually, the turbulence effect on the performance of the land-based wind turbine has drawn the attention of researchers. Devinant et al. (2002) measured the aerodynamics of a fixed aerofoil in high turbulence. They revealed the strong dependence of the aerodynamic properties on the turbulence intensity, especially in the angle of attack range corresponding to aerofoil stall. Chamorro et al. (2015) launched an experiment to study the unsteady behaviour of a full-scale 2.5 WM wind turbine in turbulent inflow. A similar relationship was observed by Lee et al. (2018) in the field measurement of a small vertical-axis wind turbine installed on the rooftop of a building. Barthelmie et al. (2007) measured the power losses due to wake-induced turbulence at the Middelgrunden wind farm. Approximate $10 \%$ energy losses were observed due to wakes. Based on the field measurement at the Nysted wind farm, Barthelmie and Jensen (2010) also concluded that the energy absorption was strongly dependent on the turbulence intensity. Recently, the offshore wind community begins to realize the importance of inflow turbulence. Li et al. (2018) simulated the power production of a floating wind turbine in full turbulent wind field.

In the realistic turbulent wind, the wind speed not only varies with the time (turbulence intensity), but also with the space (coherence and wind shear). Although researches on the turbulence effect have been documented, the above three factors are frequently investigated altogether and their individual effect is not fully understood yet. This study aims to investigate the individual effect of wind shear, turbulence intensity and coherence on the dynamic and structural performances of offshore floating wind turbines. First, the full turbulent wind model will be interpreted in details. Afterwards, aero-hydroservo coupled analysis is conducted in time-domain to capture the performance of a semisubmersible floating wind turbine with different levels of wind shear, turbulence intensity and coherence. 


\section{2. Model Description}

A semisubmersible floating wind turbine, namely the OC4 DeepCwind semisubmersible concept (Robertson et al., 2014), is considered here. As shown in Fig. 1, the DeepCwind concept mainly consists of the wind turbine, the supporting structure, and the mooring line system.

The wind turbine is the NREL 5WM baseline wind turbine (Jonkman et al., 2009), which incorporates a variable-speed torque controller and a blade pitch controller to regulate the power generation based on the operational state. The diameter of the rotor is $126 \mathrm{~m}$, and hub height is $90 \mathrm{~m}$. Please refer to (Jonkman et al., 2009) for more detailed parameters of the reference wind turbine.

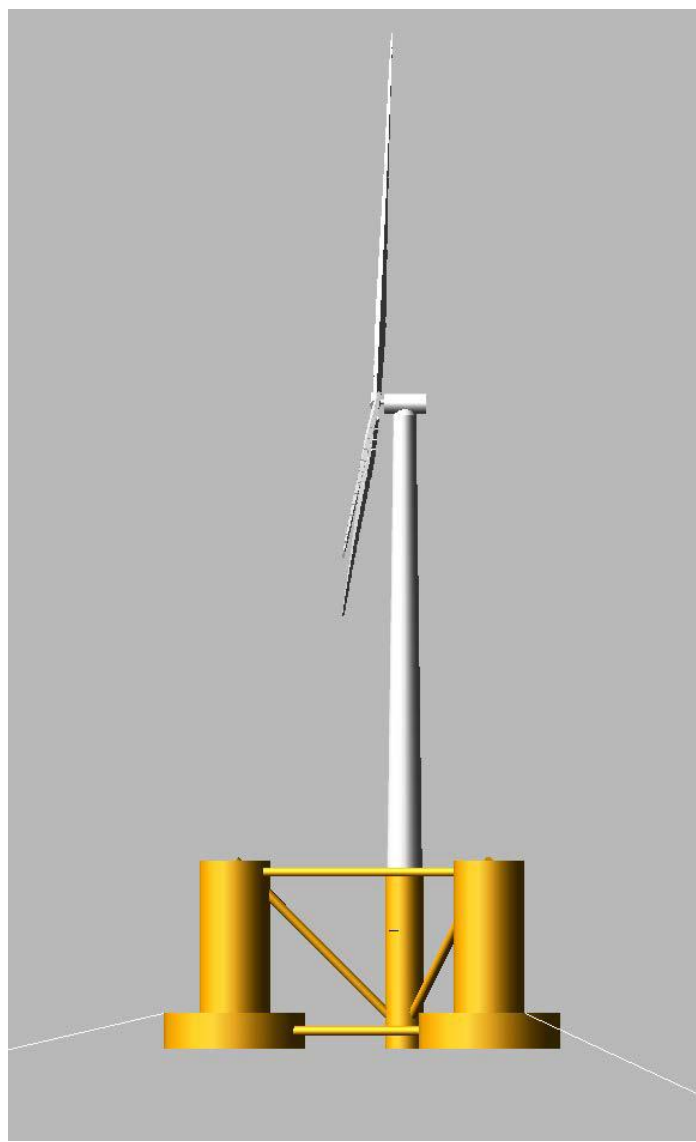

Fig. 1. DeepCwind floating wind turbine system design (Coulling et al., 2013).

The supporting structure is a semisubmersible platform, made up of three main offset columns, one central column, as well as a series of diagonal cross and horizontal bracing components. The main scantlings of the semisubmersible are listed in Table 1. 

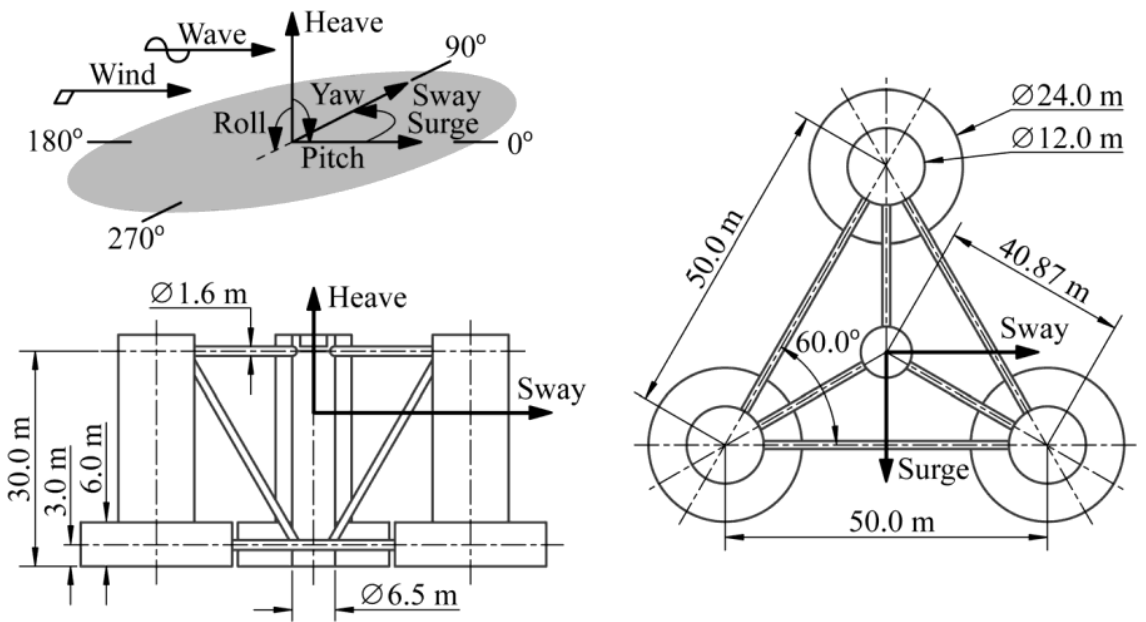

Fig. 2. Main dimensions of the submersible platform (Coulling et al., 2013).

Table 1. Main scantlings of the platform.

\begin{tabular}{cc}
\hline Term & Value \\
\hline Draft & $20 \mathrm{~m}$ \\
Elevation of platform top & $10 \mathrm{~m}$ \\
Elevation of offset columns & $12 \mathrm{~m}$ \\
Spacing between offset columns & $50 \mathrm{~m}$ \\
Length of upper columns & $26 \mathrm{~m}$ \\
Length of base columns & $6 \mathrm{~m}$ \\
Depth to top of base columns & $14 \mathrm{~m}$ \\
Diameter of main column & $6.5 \mathrm{~m}$ \\
Diameter of offset (upper) columns & $12 \mathrm{~m}$ \\
Diameter of base columns & $24 \mathrm{~m}$ \\
Platform mass & $13,473,000 \mathrm{~kg}$ \\
Displacement & $13,986.8 \mathrm{~m} 3^{3}$ \\
Centre of mass & $(0 \mathrm{~m}, 0 \mathrm{~m},-13.5 \mathrm{~m})$ \\
Platform roll inertia & $6.827 \times 10^{9} \mathrm{~kg} \cdot \mathrm{m}^{2}$ \\
Platform pitch inertia & $6.827 \times 10^{9} \mathrm{~kg} \cdot \mathrm{m}^{2}$ \\
Platform yaw inertia & $1.226 \times 10^{10} \mathrm{~kg} \cdot \mathrm{m}^{2}$ \\
\hline
\end{tabular}

The floating wind turbine is displaced at sea site with a water depth of $200 \mathrm{~m}$. Three catenary lines are used to hold the platform against sea waves and offshore wind. The three mooring lines are oriented symmetrically at $60^{\circ}, 180^{\circ}$, and $300^{\circ}$ about the vertical axis. Fairleads are connected to the tops of ballast tanks. The relevant properties of mooring lines are outlined in Table 2.

Table 2. Properties of mooring line.

\begin{tabular}{cc}
\hline Term & Value \\
\hline Depth to anchor & $200 \mathrm{~m}$ \\
Depth to fairlead & $14 \mathrm{~m}$ \\
Radius to anchor & $837.6 \mathrm{~m}$ \\
Radius to fairlead & $40.868 \mathrm{~m}$ \\
Unstretched mooring line length & $835.5 \mathrm{~m}$ \\
Mooring line diameter & $0.0766 \mathrm{~m}$ \\
Equivalent line mass density & $113.35 \mathrm{~kg} / \mathrm{m}$ \\
Equivalent mooring line extensional stiffness & $753.6 \mathrm{MN}$ \\
\hline
\end{tabular}




\section{Turbulent Wind Model}

As shown in Fig. 3, two comparative wind fields are generated. The first one is a steady uniform wind field, where the wind inflow is constant in both time and space scales. The second wind field is turbulent, where the wind inflow varies with not only time but also with space. The second wind field is turbulent, in terms of wind shear, time-scale inflow variation and space-scale inhomogeneity.

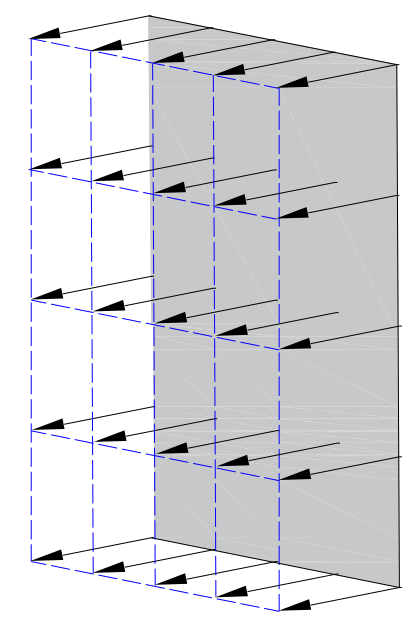

a

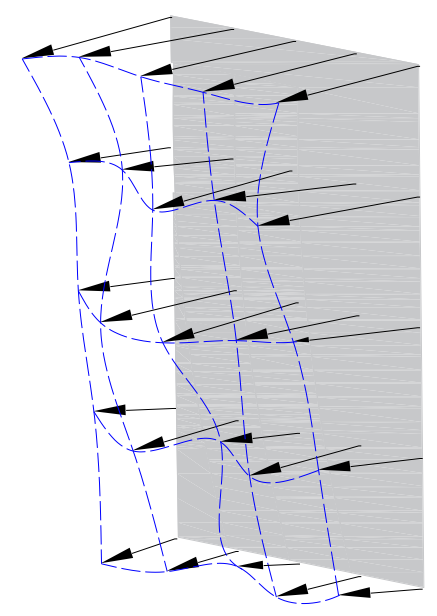

$\mathrm{b}$
93

Fig. 3. Generated wind fields. (a) steady wind field; (b) turbulent wind field.

The wind shear describes how the near-ground wind varies vertically with the height. In the present research, the power-law model is used to represent the wind profile,

$$
u(z)=u\left(\frac{z}{90}\right)^{\alpha}
$$

where $\alpha$ is the exponent parameter. Fig. 4 shows the wind profiles with different values of $\alpha$. The wind shear becomes more significant when $\alpha$ increases. When $\alpha$ is equal to 0 , the wind shear is omitted and the wind field reduces to the uniform one. In the present simulation, $\alpha=0.15$ is used. 


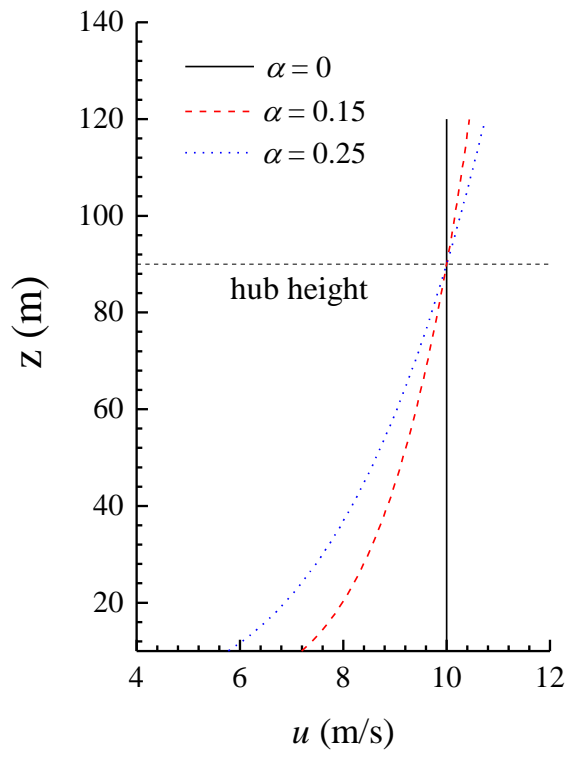

Fig. 4. Wind profile.

The wind inflow is also time-dependent and commonly a spectral method is used to model the timescale inflow variation. The IEC Kaimal turbulence model (International Electrotechnical Commission, 2015) is used here

$$
S(f)=\frac{4 \sigma^{2} L / u}{(1+6 f \cdot L / u)^{5 / 3}}
$$

where $f$ is the cyclic frequency and $L$ is an integral scale parameter dependent on the hub height. $u$ is the mean wind speed at hub height. $\sigma$ can be estimated by the turbulence intensity $T I$ (\%)

$$
\sigma=\frac{T I}{100} u
$$

The turbulence intensity represents the turbulence level, namely how strong the wind varies with time. In the present simulation, the turbulence intensity is set to $10 \%$. Fig. 5 displays the spectra of rated wind $(u=11.4 \mathrm{~m} / \mathrm{s})$. As shown, the low-frequency oscillations dominate the wind.

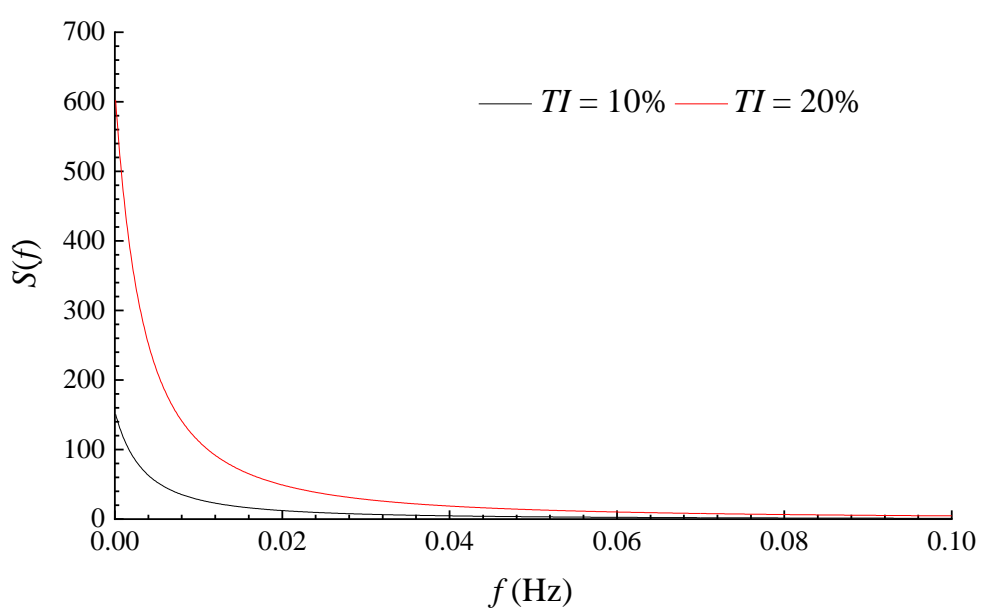


Apart from the variation in time scale, the wind velocity is also inhomogeneous across the rotor plane at each time instant. This is due to the phase differences between two points in the wind field so that the time-scale phase difference leads to the space-scale inhomogeneity. The IEC coherence model is used to represent the correlation between two arbitrary points.

$$
\begin{aligned}
& \operatorname{Coh}_{i, j}(f)=\frac{\left|S_{i, j}(f)\right|}{\sqrt{S_{i}(f) S_{j}(f)}} \\
& \operatorname{Coh}_{i, j}(f)=\exp \left[-12 \sqrt{\left(\frac{f \cdot r}{u}\right)^{2}+\left(0.12 \frac{r}{L_{c}}\right)^{2}}\right] \\
& L_{c}=\min (60, \text { hub height })
\end{aligned}
$$

where $S_{i, j}$ is the cross-spectra defining the correlation of the random wind speed at points $i$ and $j, r$ is the distance between the two points. $L_{c}$ is the coherence scale parameter replying on the hub height.

\section{Dynamic Analysis}

\subsection{Numerical model}

The aero-hydro-servo-elastic coupled simulation code FAST (Jonkman and Buhl Jr, 2005) developed by the National Renewable Energy Laboratory (NREL) is used to simulate the dynamic performance of the DeepCwind floating wind turbine.

Assuming that the wave fluid is ideal, the wave-structure is addressed in the framework of potential flow theory. The wave radiation force is calculated with the convolution term to consider the free surface memory effect. Since the natural period of horizontal motion of the floating wind turbine is sufficiently long, second-order drift wave forces are also considered to capture the low-frequency responses of the floating wind turbine.

The blade element momentum (BEM) method is used to compute the wind force acting on the rotor. The blade is separated into a set of elements, and the interactions between neighbouring elements are neglected. By seeking the so-called induced velocity, the aerodynamic load on each element is determined using the lift and drag coefficients of the aerofoil. For an offshore floating wind turbine, both the platform motions and wind turbulence produce unsteadiness of the inflow seen by the rotor. The unsteady effect is accounted by the dynamic wake model developed by Minnema (1998), which can be regarded as a correction to the induced velocity determined by the BEM method.

A variable-speed torque controller and a blade pitch controller are incorporated to the wind turbine. The variable-speed torque controller is active in below-rated operational state. The control algorithm is to maximize the power output by adjusting the rotor speed while the blade pitch angle is fixed at zero. One the contrary, the blade-pitch controller works in over-rated state to regulate generator power by increasing the pitch angle of the blade. 
The lumped-mass model is used for the dynamics of mooring lines connected to the floating platform. The mooring line is divided into a set of evenly-sized segments, which are represented by connected nodes and spring-damper systems. Each segment is divided into two components and the properties are assigned and lumped to the two nodes at each end of that segment, respectively. The connections between adjacent nodes are represented by damper-spring systems. Only the axial properties of the mooring lines are accounted whereas the torsional and bending properties are neglected.

\subsection{Short-term extreme response}

The extreme responses are estimated based on the mean up-crossing rate method. In an arbitrary time interval $T$, it can be assumed that the random number of up-crossing is approximated by the Poisson distribution on condition that the up-crossing is statistically independent. Once a level $y$ is selected, the distribution of extreme value $y_{\max }$ for a random signal $y(t)$ is described as

$$
P\left(y_{\max } \leq y\right)=\exp \left(-\int_{0}^{T} v^{+}(y, t) d t\right)
$$

where $v^{+}(y, t)$ is the up-crossing rate corresponding to level $y$, which denotes the instantaneous frequency of the positive slop crossings of the defined level. In this circumstance, the probability of $y_{\max }$ exceeding a defined level $y$ is given by

$$
\begin{aligned}
& P\left(y_{\max }>y\right)=1-\exp \left(-\hat{v}^{+}(y) T\right) \\
& \hat{v}^{+}(y)=\frac{1}{T} \int_{0}^{T} v^{+}(y, t) d t
\end{aligned}
$$

The mean up-crossing rate $\hat{v}^{+}(y)$ can be easily obtained from the time series of the signal that is going to be analysed. For example, if we have $k$ independent realizations of the random process and let $n_{j}^{+}(y, T)$ denote the number of up-crossings in realization $j$, then the sample-based mean up-crossing rate is given by

$$
\hat{v}^{+}(y) \approx \bar{v}^{+}(y)
$$

$$
\bar{v}^{+}(y)=\frac{1}{k T} \sum_{j=1}^{k} n_{j}^{+}(y, T)
$$

Eq. (7) is the basic formula to approximate the mean up-crossing rate $\hat{v}^{+}(y)$ through numerical simulations. If the defined level $y$ is not very high, then just a few simulation realizations of the random process will produce satisfactory approximation. Nevertheless, extensive simulations are required to evaluate the extreme values in the tail region. To save computation resources, the extrapolation method proposed by Naess and Gaidai (2009) is used in this study to extrapolate the mean up-crossing rate corresponding to high level $y$. The extrapolation method is based on the observation of marine structures so that it is applicable in this study. The mean up-crossing rate is approximated by

$$
\begin{aligned}
& \bar{v}^{+}(y) \approx v_{f i t}^{+}(y) \\
& v_{f i t}^{+}(y)=q \cdot \exp \left\{-a(y-b)^{c}\right\}, y \geq y_{0}
\end{aligned}
$$


where $q, a, b$ and $c$ are all constant values. $y_{0}$ is the lower limit of the sampled data used for the extrapolation. To ensure that the extrapolated rate is reliable, the $95 \%$ confidence interval $(C I)$ of the raw rate is examined:

$$
C I_{ \pm}(y)=\bar{v}^{+}(y) \pm \frac{1.96 s(y)}{\sqrt{k}}
$$

$$
s^{2}(y)=\frac{1}{k-1} \sum_{j=1}^{k}\left(\frac{n_{j}^{+}(y, T)}{T}-\bar{v}^{+}(y)\right)^{2}
$$

In the present research, the extrapolated up-crossing rate is based on 6 independent numerical realizations $(k=6), y_{0}=($ mean+std) is used, where 'mean' is the average mean response of the 6 numerical realizations; 'std' is the average standard deviation of the 6 numerical realizations. Please note that $y_{0}$ varies with the load case so as to ensure the extrapolated rate is within the confidence interval. To put more emphasis on the more reliable sampled data, the weight factor proposed by Naess and Gaidai (2009) is used here

$$
\Theta=\sum_{j=1}^{N} w_{j}\left|\log \left(\bar{v}^{+}\left(y_{j}\right)\right)-\log (q)+a\left(y_{j}-b\right)^{c}\right|^{2}
$$

where $\Theta$ is the mean square error; $w_{j}=\left|\log \left(C I_{+}\left(y_{j}\right)\right)-\log \left(C I_{-}\left(y_{j}\right)\right)\right|^{-2}$ is the weight factor. The least square optimization method is used to get $q, a, b$ and $c$ by minimizing $\Theta$.

Fig. 6 gives an example of the extrapolated up-crossing rate for the tower base bending moment under rated steady wind. As shown, the extrapolated rate is located within the $95 \%$ confidence interval indicating that the extrapolation is reliable. Hereinafter, the extreme value corresponding to $v_{f i t}^{+}=10^{-5}$ will be used to represent the short-term extreme response.

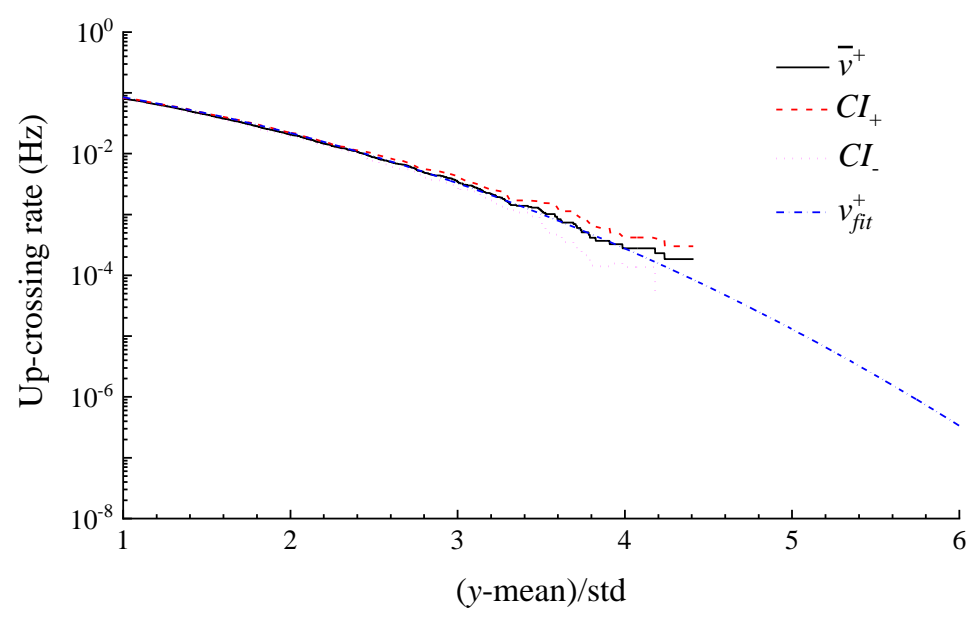

Fig. 6. Extrapolation of the up-crossing rate of the tower base bending moment under rated steady wind based on 6 numerical realizations.

\subsection{Simulation setup}

The aero-hydro-servo-elastic coupled dynamic analysis is conducted for a set of wind speeds, covering different operation states of the wind turbine. The wind speed refers to that measured at the 
hub centre $(90 \mathrm{~m})$. The turbulent wind field is generated using the TurbSim (NWTC Information Portal,

197 2016). Due to the platform motions, the wind turbine moves a lot during the simulation, and a wind grid

198 with dimension $180 \mathrm{~m} \times 180 \mathrm{~m}$ is generated to cover the movement range of the rotor (see Fig. 7). 441 points $(21 \times 21)$ are uniformly distributed across the wind grid, at which the time-series of wind speed are generated. Table 3 summaries the environmental conditions considered in the present simulation.

For each environmental condition, the simulation runs for a total length of 3800 seconds, and only the last 1-hour data will be collected to get rid of the transient effects in the early simulation stage. The simulation time increment is set to $0.0125 \mathrm{~s}$.

\begin{tabular}{llll}
\hline & $U_{w}$ & $H_{s}$ & $T_{p}$ \\
\hline Below-rated & $8 \mathrm{~m} / \mathrm{s}$ & $4 \mathrm{~m}$ & $6 \mathrm{~s}$ \\
Rated & $11.4 \mathrm{~m} / \mathrm{s}$ & $5 \mathrm{~m}$ & $8 \mathrm{~s}$ \\
Over-rated & $14 \mathrm{~m} / \mathrm{s}$ & $6 \mathrm{~m}$ & $10 \mathrm{~s}$ \\
\hline
\end{tabular}

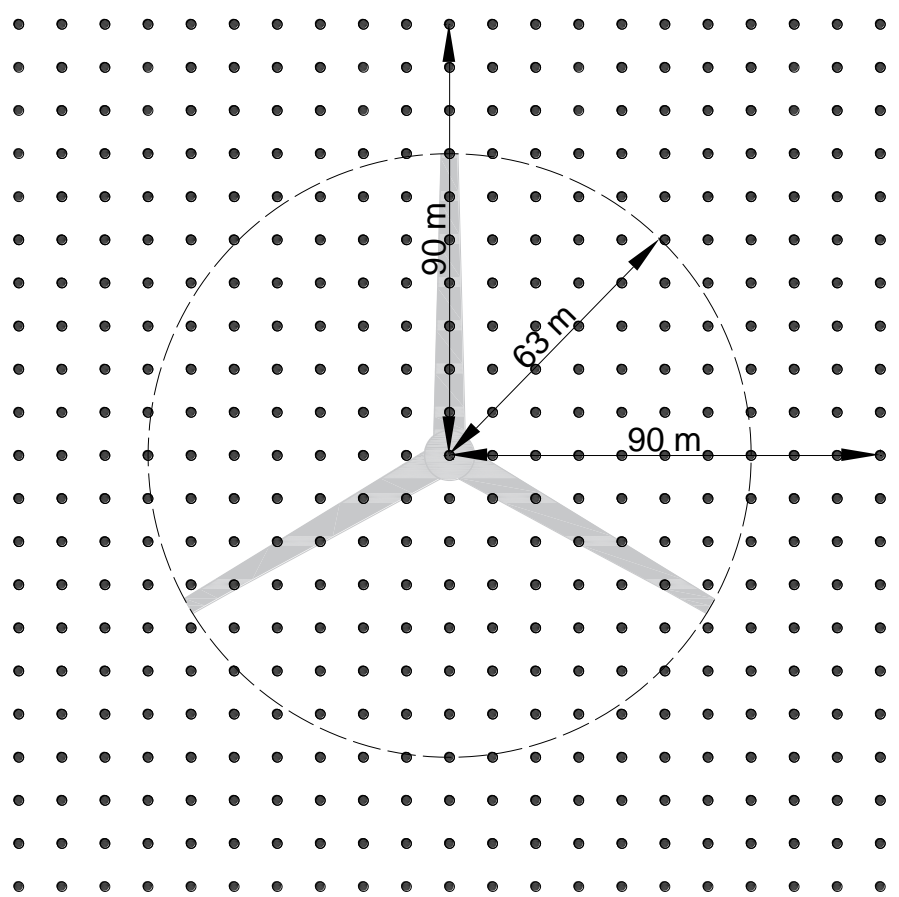

Fig. 7. Wind grid.

\section{5. Simulation Results}

\subsection{Dynamic response in turbulent flow}

First, the dynamic performance of the reference floating wind turbine in the uniform wind and the turbulent wind are compared.

212 Table 4 summaries the standard deviations of the platform global motions under various operational states (below-rated, rated and over-rated) when the two comparative wind flow conditions are considered. It is clearly shown that the platform surge and pitch motions are increased substantially, regardless of the mean wind speed. Since the wind mainly induces horizontal loads, the turbulence has 
216 a negligible effect on platform heave motion. Fig. 8 and Fig. 9 display the response feature of surge and 217 pitch motions, respectively. In the steady wind, the platform motion is mainly induced at wave 218 frequency range and resonant frequency. In the turbulent inflow, the platform motion is excited a lot at 219 the resonant frequency whereas the wave frequency motion is hardly varied. It indicates that the 220 aerodynamic turbulence effect is not effective at all on wave-induced response. Similar phenomenon 221 has been documented previously in (Hu et al., 2016).

222 Table 4. Standard deviation of platform motions

\begin{tabular}{ccccccc}
\hline & \multicolumn{2}{c}{ Below-rated } & \multicolumn{2}{c}{ Rated } & \multicolumn{2}{c}{ Over-rated } \\
\hline & $\begin{array}{c}\text { Turbulent } \\
\text { wind }\end{array}$ & $\begin{array}{c}\text { Steady } \\
\text { wind }\end{array}$ & $\begin{array}{c}\text { Turbulent } \\
\text { wind }\end{array}$ & $\begin{array}{c}\text { Steady } \\
\text { wind }\end{array}$ & $\begin{array}{c}\text { Turbulent } \\
\text { wind }\end{array}$ & $\begin{array}{c}\text { Steady } \\
\text { wind }\end{array}$ \\
\cline { 2 - 7 } Surge & 1.11 & 0.94 & 1.41 & 1.12 & 1.18 & 0.90 \\
Heave & 0.06 & 0.06 & 0.13 & 0.13 & 0.29 & 0.28 \\
Pitch & 0.32 & 0.21 & 0.57 & 0.40 & 0.72 & 0.54 \\
\hline
\end{tabular}

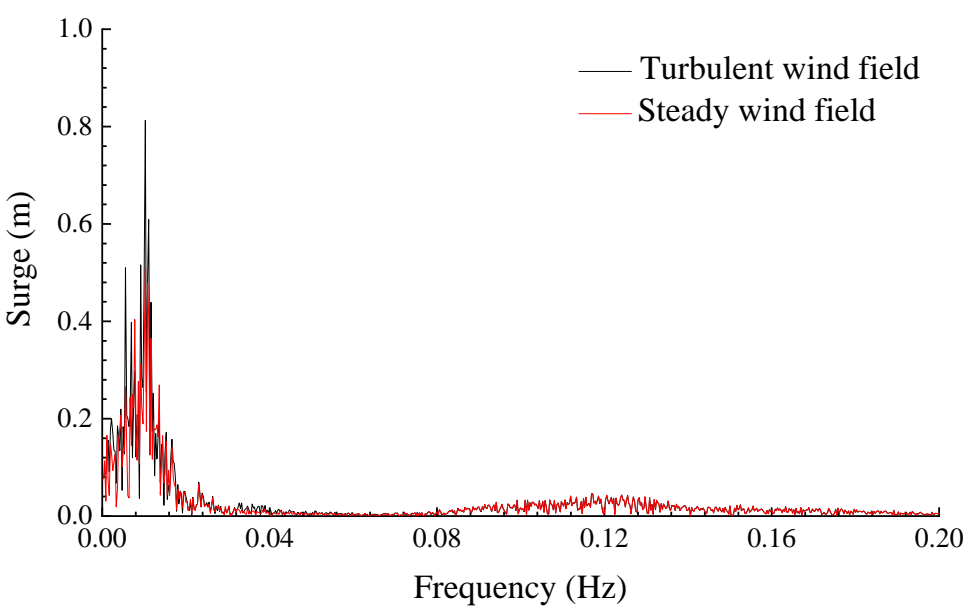

Fig. 8. FFT analysis of platform surge motion.

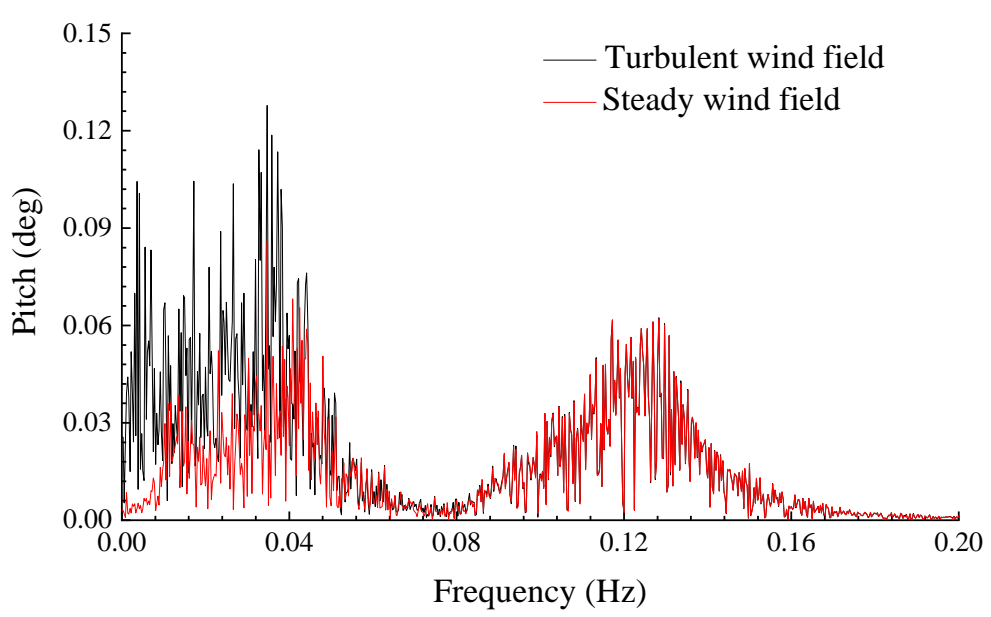

Fig. 9. FFT analysis of platform pitch motion, rated operation state.

Apart from platform motions, the effect of turbulent inflow on structural loads is also considerable. Fig. 10 plots the FFT analysis result of the tower base fore-aft bending moment in the three operation states. Although the wave-frequency response is generally independent from the turbulent inflow, the low-frequency and the high-frequency are quite sensitive to the turbulent inflow. In all three operation 
scenarios, the bending moment response at low-frequency range is excited the most. It is attributed to the dominating slow-varying inflow in the turbulent wind field (see Fig. 5). In the meanwhile, the blades experience wind speed variation over the rotation process due to the spatial inhomogeneity, leading to the high-frequency range response. Similar conclusions can be drawn from the fairlead tension force, which is displayed in Fig. 11. The aerodynamic loads are not applied to the fairlead directly but through the platform movement. Therefore, high-frequency fairlead tension force response is not observed since the platform's natural frequency is sufficiently low.
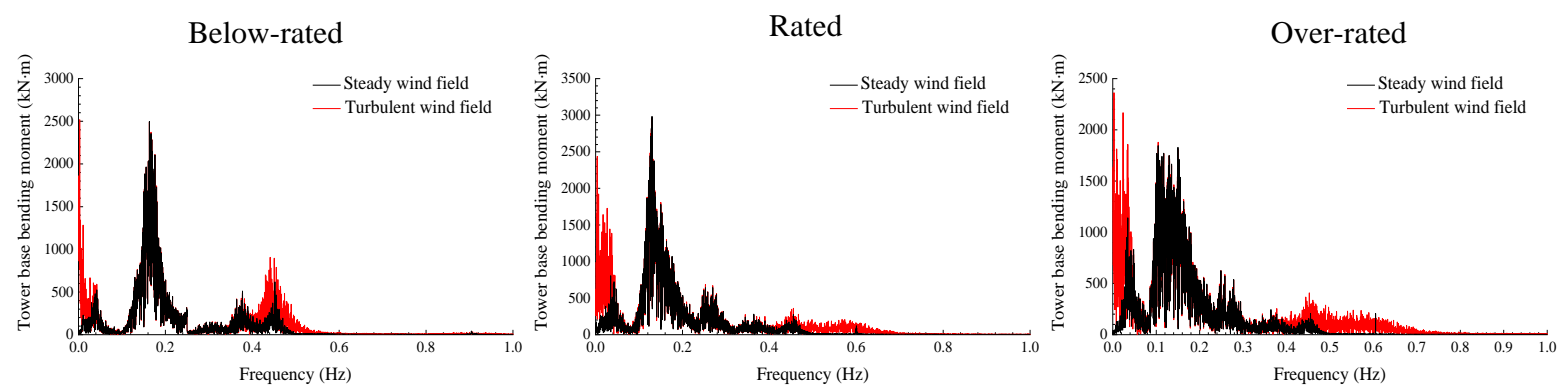

Fig. 10. FFT analysis of tower base fore-aft bending moment.
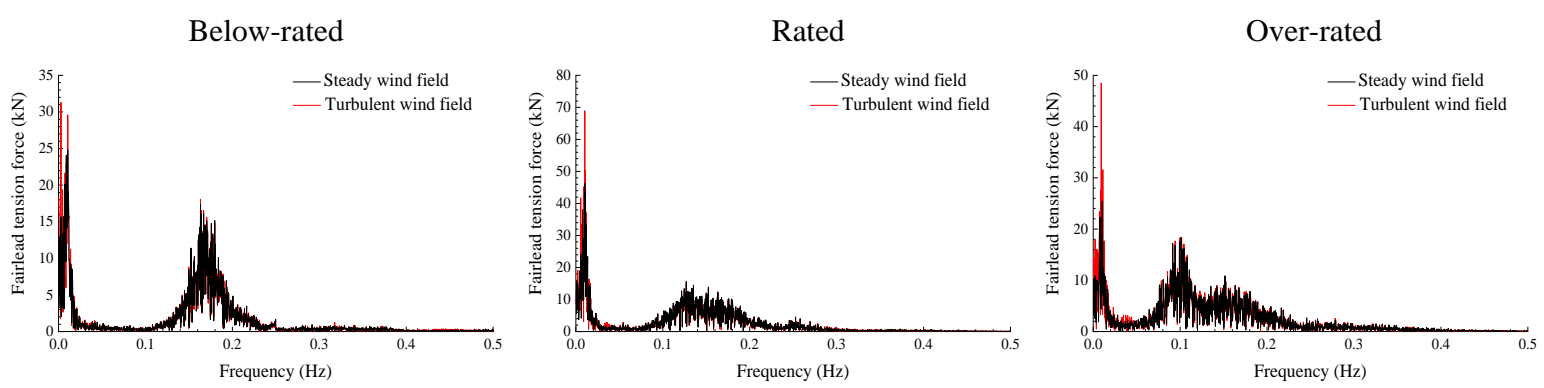

241

242

243

244

245

246

247

248

249

250

251

252

253

Fig. 11. FFT analysis of fairlead tension force.

Since the floating wind turbine is subject to identical wave excitations in the steady wind and the turbulent wind, the amplitude of platform motions and structural loads could be purely attributed to the wind force. Fig. 12 illustrates the response character of rotor thrust force. The majority of response energy is located within the low-frequency range, mainly induced by the turbulence intensity. Besides, the response is also observed around $0.44 \mathrm{~Hz}$, namely the 3P frequency of the rotor speed. The $3 \mathrm{P}$ frequency response is induced by the spatial inhomogeneity of the wind field since the wind speed seen by the blade experiences variation during the rotation process. Two aspects contribute to the spatial inhomogeneity. The first one is the wind shear, representing how the wind inflow varies vertically with the height. Secondly, the phase lag between two points in the rotor plane also leads to the space-scale inflow variation, and it is represented by the coherence model. In the following part, the individual effect of wind shear, turbulence intensity and coherence will be clarified. 


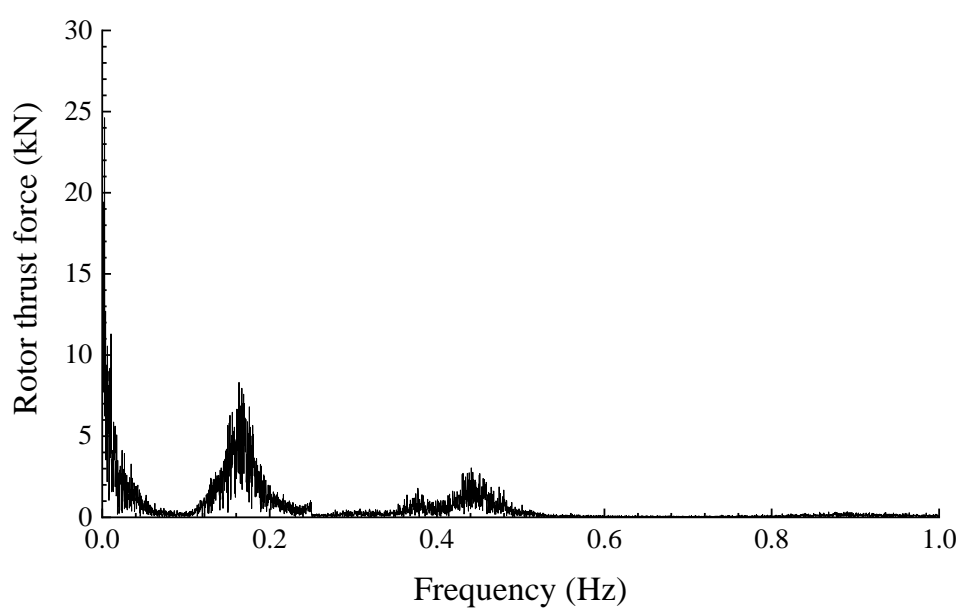

Fig. 12. FFT analysis result of thrust force in turbulent wind field, below-rated operation state.

\subsection{Wind shear effect}

Fig. 13 and Fig. 14 plot the platform surge and pitch motions, respectively. It appears that the platform motions are not sensitive to the wind shear at all. Despite that the wind shear exponent increases from 0 to 0.25 , the responses of surge and pitch motions are hardly varied. When a blade is experiencing the high wind velocity region (up half of the rotor plane), the other two blades are within low wind velocity region (down half of the rotor plane). In this case, the resultant thrust force induced by the three blades remains relatively stable. Consequently, the wind shear has a negligible influence on the platform motions.
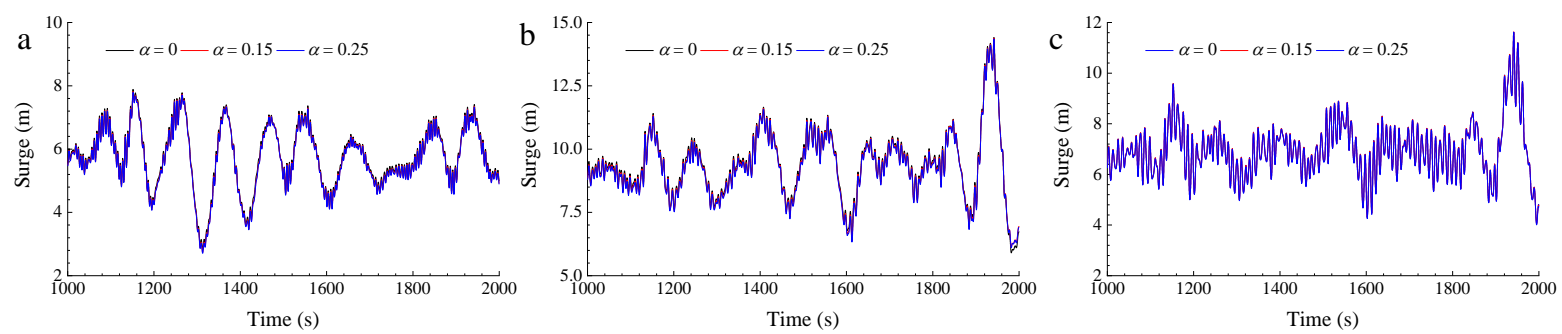

Fig. 13. Time series of platform surge motions. (a) below-rated condition; (b) Rated condition; (c) Over-rated condition.
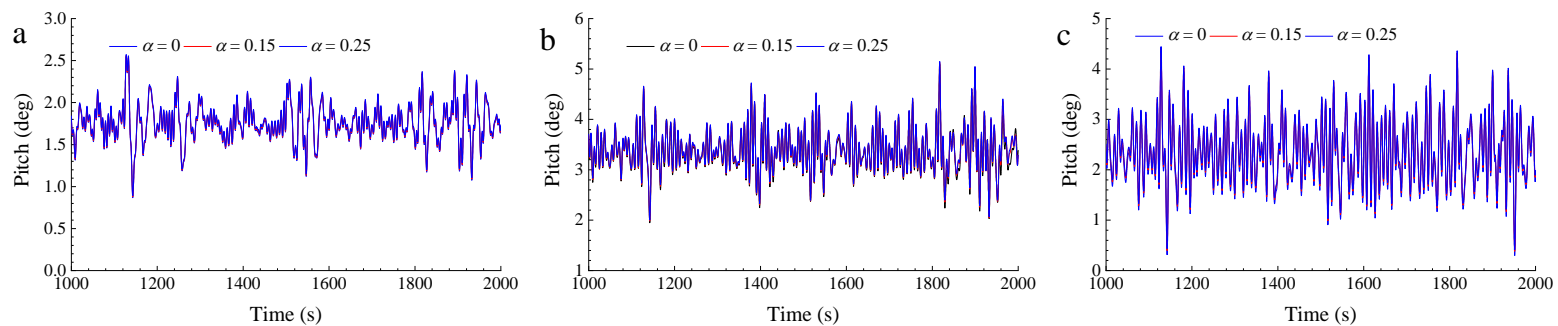

Fig. 14. Time series of platform pitch motions. (a) below-rated condition; (b) Rated condition; (c) Over-rated condition.

Fig. 15 and Fig. 16 demonstrate the extreme tower base bending moment and the extreme fairlead tension in the presence of wind shear, respectively. As discussed above, the rotor thrust varies hardly with the wind shear, and thereby the extreme tower base fore-aft bending moment and the extreme fairlead tension remains nearly unchanged regardless of the wind shear. 


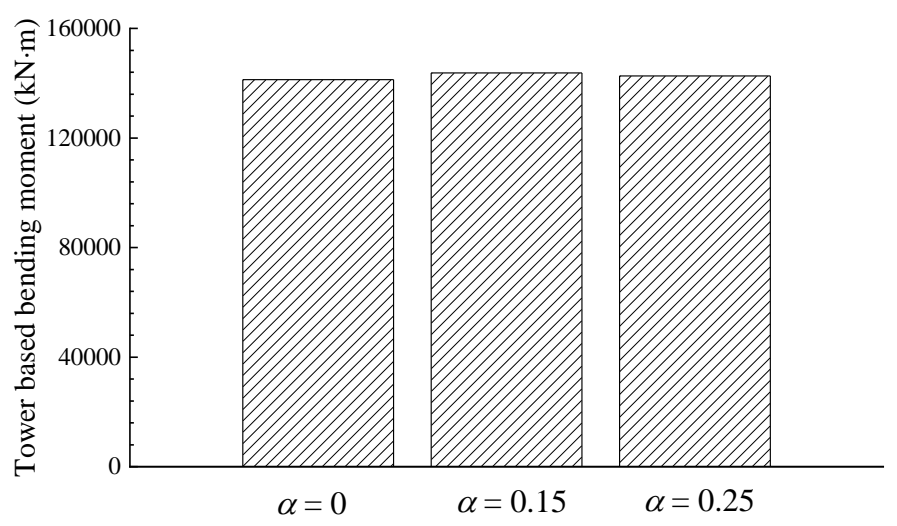

Fig. 15. Extreme tower base fore-aft bending moment, rated operation condition.

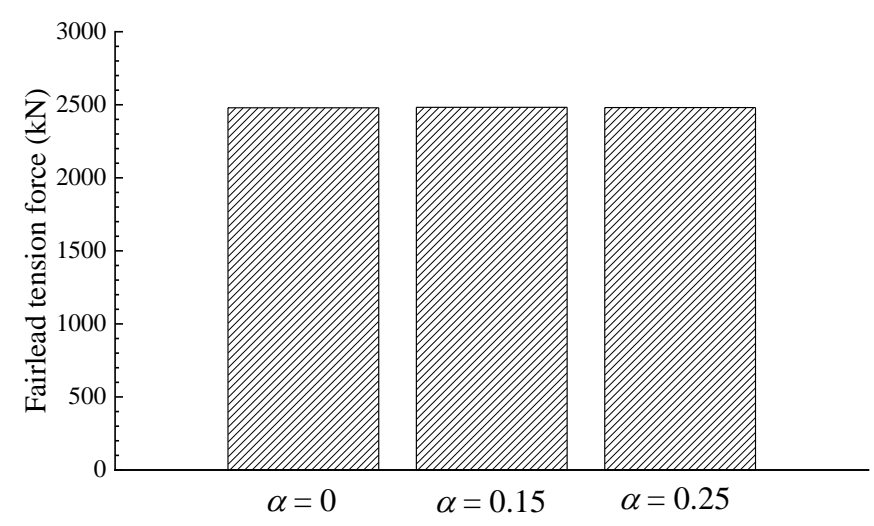

Fig. 16. Extreme fairlead tension, rated operation condition.

Although the platform motions and the structural loads at tower base and fairlead are not sensitive to the wind shear, the local loads at blade root depend strongly on the wind shear. According to the time series plotted in Fig. 17, the out-of-plane bending moment at blade root becomes quite unstable in the presence of large wind shear. As explained before, the blade will experience high-speed and low-speed region alternately due to the wind shear. Although the resultant force of the three blades remains stable, the load applied on each blade varies violently.

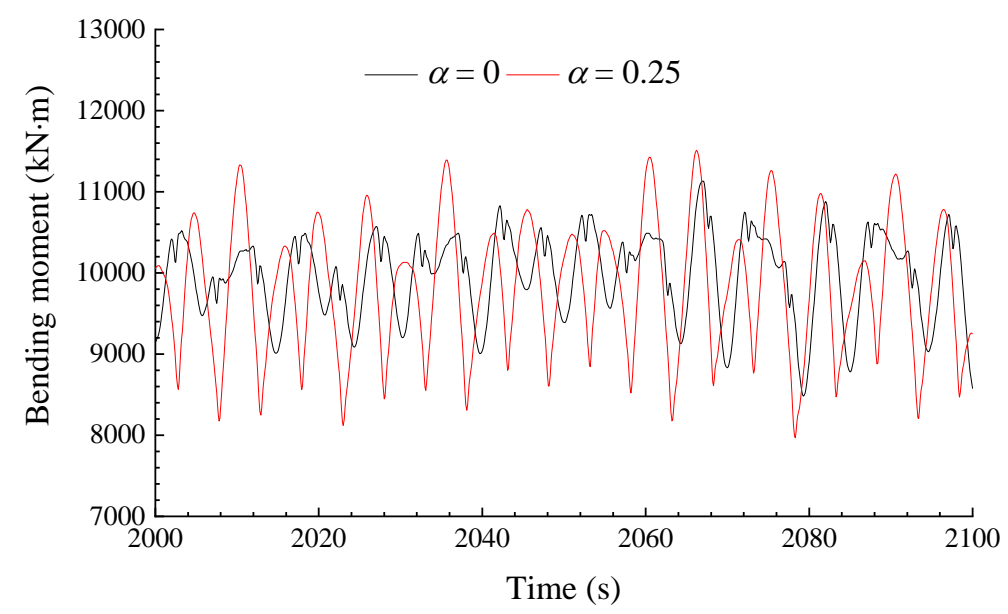

Fig. 17. Times series of blade root bending moment. 


\subsection{Turbulence intensity effect}

The performances of the floating wind turbine with different turbulence intensities (10\% and 20\%) are examined in this sub-section. The law exponent parameter $\alpha$ is set to zero to eliminate the wind shear effect.

Fig. 18 plots the time series of platform surge and pitch motions under below-rated wind. It is easy to identify that the platform motions become increasingly violent when the turbulence intensity increases to $20 \%$. To interpret the turbulence intensity effect more clearly, the time series of platform motions are analyzed with the FFT method and the results are presented in Fig. 19. The turbulence intensity effect is only observed within the low-frequency region (lower than the resonant frequency). In the right side of the vertical dash line (representing the resonant frequency), the two curves match well. When the turbulence intensity increases, the resonant response is somewhat amplified. Moreover, the quasi-static response at very low frequency range $\left(10^{-4} \mathrm{~Hz} \sim 10^{-3} \mathrm{~Hz}\right)$ is further induced.
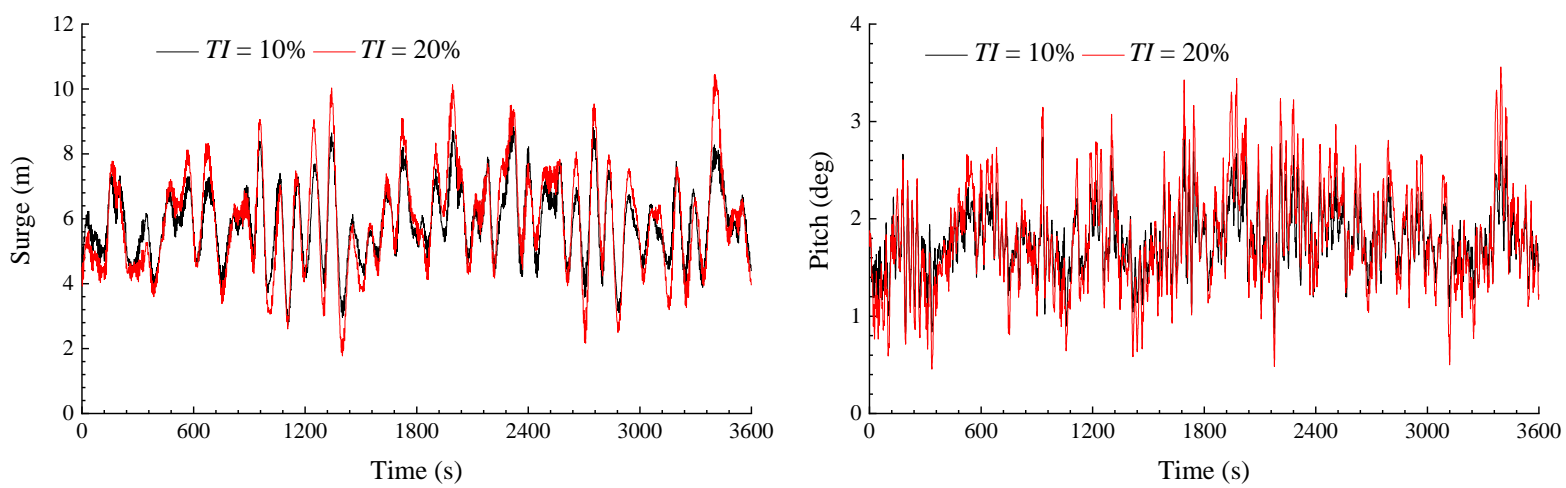

Fig. 18. Time series of platform motions, below-rated.

298

299
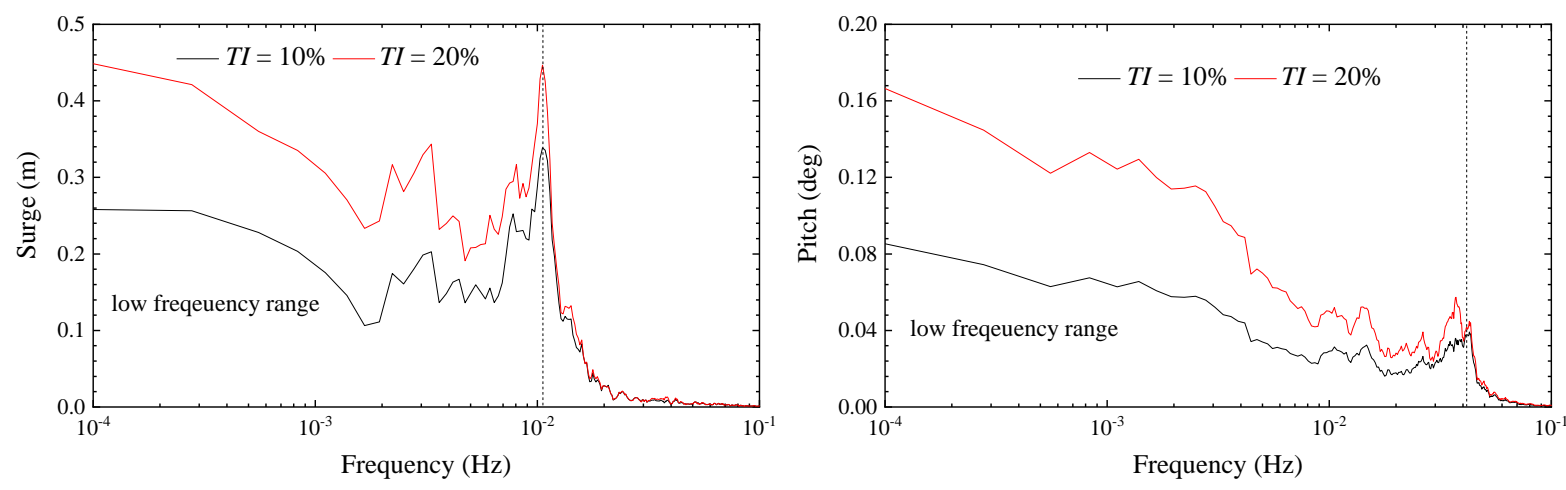

Fig. 19. FFT analysis results of platform motions, below-rated.

In addition to the platform motions, the turbulence intensity also has observable consequences for structural loads. According to Table 5, the extreme responses of the tower base bending moment and the fairlead tension increase considerably with the turbulence intensity.

Table 5. Short-term extreme responses

\begin{tabular}{lll}
\hline & $T I=10 \%$ & $T I=20 \%$ \\
\hline Tower base bending moment $(\mathrm{kN} \cdot \mathrm{m})$ & $1.09 \times 10^{5}$ & $1.19 \times 10^{5}$ \\
Fairlead tension force $(\mathrm{kN})$ & 2159 & 2462 \\
\hline
\end{tabular}




\subsection{Coherence structure effect}

In addition to the wind shear and the turbulence intensity, the blade also experiences inflow variation due to the inhomogeneity of the wind field and the inhomogeneity is caused by the coherence (phase difference). We adopt the hub centre as the reference point. An unsteady uniform wind field, in which the phase difference between any point and the reference point is zero, is generated to illustrate the coherence structure effect. As shown in Fig. 20, the wind speed is not uniformly distributed in the spatially coherent wind field at each time instant due to the phase lag. On the contrary, a completely coherent air inflow is uniformly distributed across the space at each time instant since the phase difference between any two points are zero. Of course, the wind speed also varies with time since the time-scale turbulence is not eliminated. Please note that, at each time instant, the reference point wind speeds of the two comparative wind fields are equal.
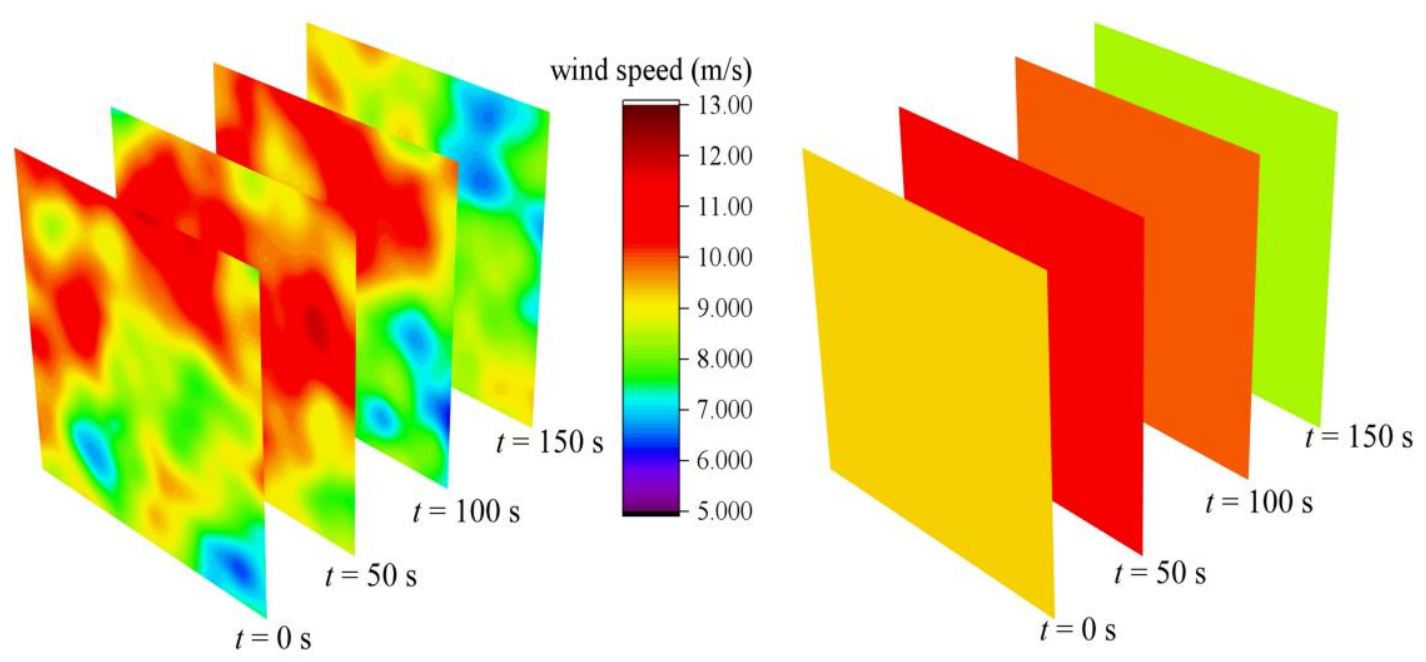

Fig. 20. How the spatial distribution of wind speed varies with time. Left: partially coherent wind field; right: completely coherent wind field.

In the unsteady uniform wind field, any two points are completely coherent whereas a realistic turbulent wind field is partially coherent. To demonstrate the coherence structure quantitatively, the proper orthogonal decomposition (POD) method is used to decompose the above two wind fields. In the present research, $21 \times 21$ points are uniformly distributed across the space so that we have total 441 measurements of wind speed at each time instant. We are to decompose $1000 \mathrm{~s}$ of wind inflow time series with the time step being $0.1 \mathrm{~s}$. Consequently, the overall wind flow data $\boldsymbol{U}=\left[\boldsymbol{u}_{1}, \boldsymbol{u}_{2}, \ldots, \boldsymbol{u}_{N}\right]$ has a dimension of $441 \times 10000$ (the $21 \times 21$ points have been re-organized). The auto-covariance matrix of $\boldsymbol{U}$ is

$$
\boldsymbol{R}=\boldsymbol{U}^{T} \cdot \boldsymbol{U}
$$

Then we have the orthonormal eigenvectors $\boldsymbol{G}=\left[\boldsymbol{g}_{1}, \boldsymbol{g}_{2}, \ldots, \boldsymbol{g}_{N}\right]$ and the eigenvalue matrix $\boldsymbol{A}$

$$
R \boldsymbol{G}=\boldsymbol{R} \Lambda
$$

Please note that eigenvalue matrix $\boldsymbol{\Lambda}$ should be re-organized if necessary, to satisfy 


$$
\Lambda_{11} \geq \Lambda_{22} \geq \cdots \geq \Lambda_{N N}
$$

332 The normalized POD modes (the orthonormal basis) is then given by

$$
\phi_{k}=\frac{\boldsymbol{g}_{k} \cdot \boldsymbol{u}_{i}}{\left\|\boldsymbol{g}_{k} \cdot \boldsymbol{u}_{i}\right\|}
$$

The first three POD modes on based 1000 seconds of numerical realizations are displayed in Fig. 21, where the two wind fields exhibit distinctive coherence structures. For the partially coherent wind field, the first POD mode is characteristic of a single major coherent structure. In higher order modes, more patterns are observed and the inhomogeneity becomes more significant. However, all the POD modes of the completely coherent wind field are exactly flat. Apparently, the coherence structure is to have an influence on the performance of the platform wind turbine.
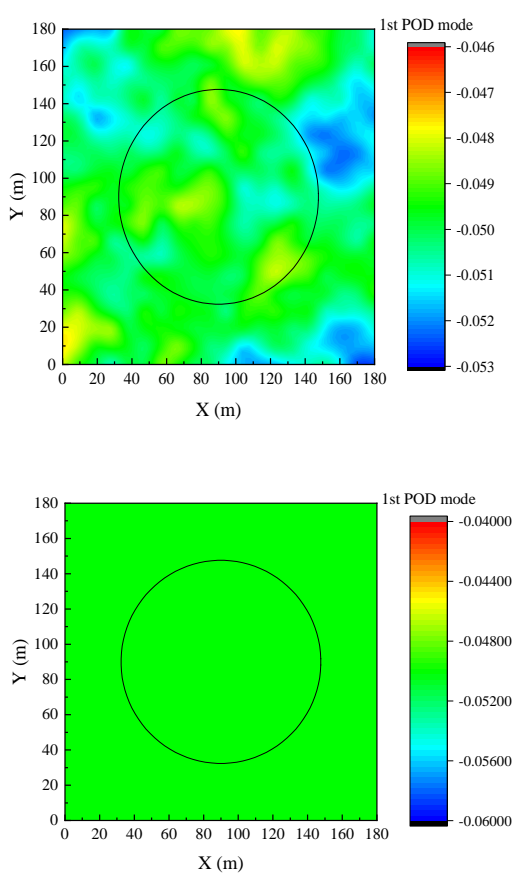

340

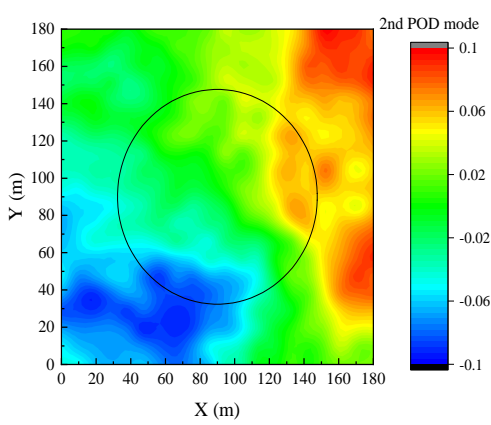

a

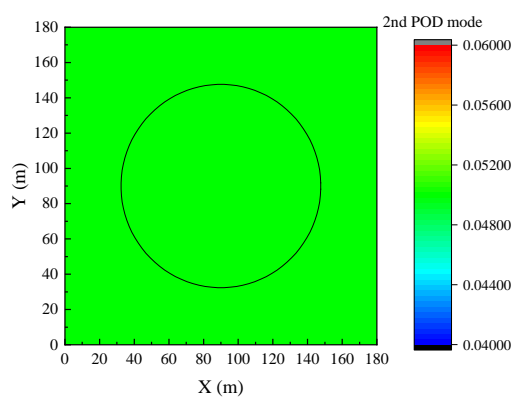

b
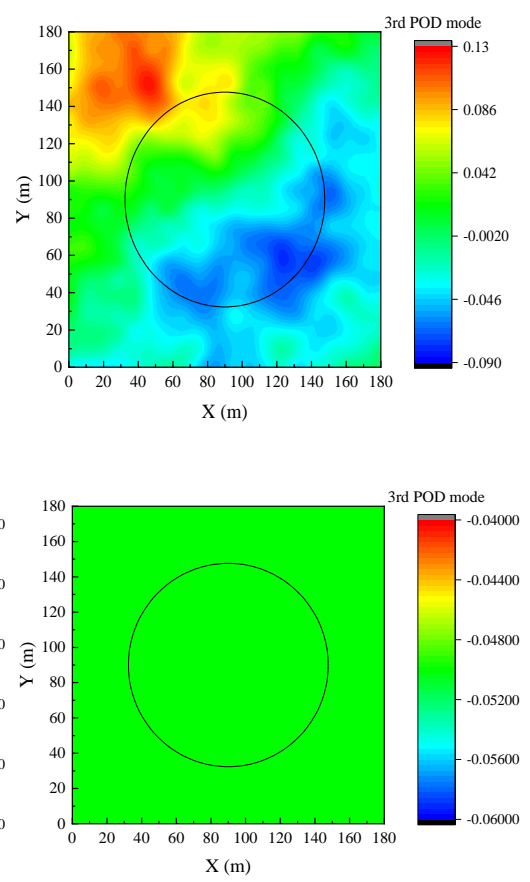

Fig. 21. Normalized POD modes of the wind field. (a) partial coherence; (b) complete coherence.

Fig. 22 illustrates the coherence structure effects on the platform motions. As shown, the pitch motion increases substantially when the points in the wind field become completely coherent with each other. According to the FFT analysis result, the resonant platform motion is amplified implying that the floating wind turbine is subject to more aerodynamic loads. 

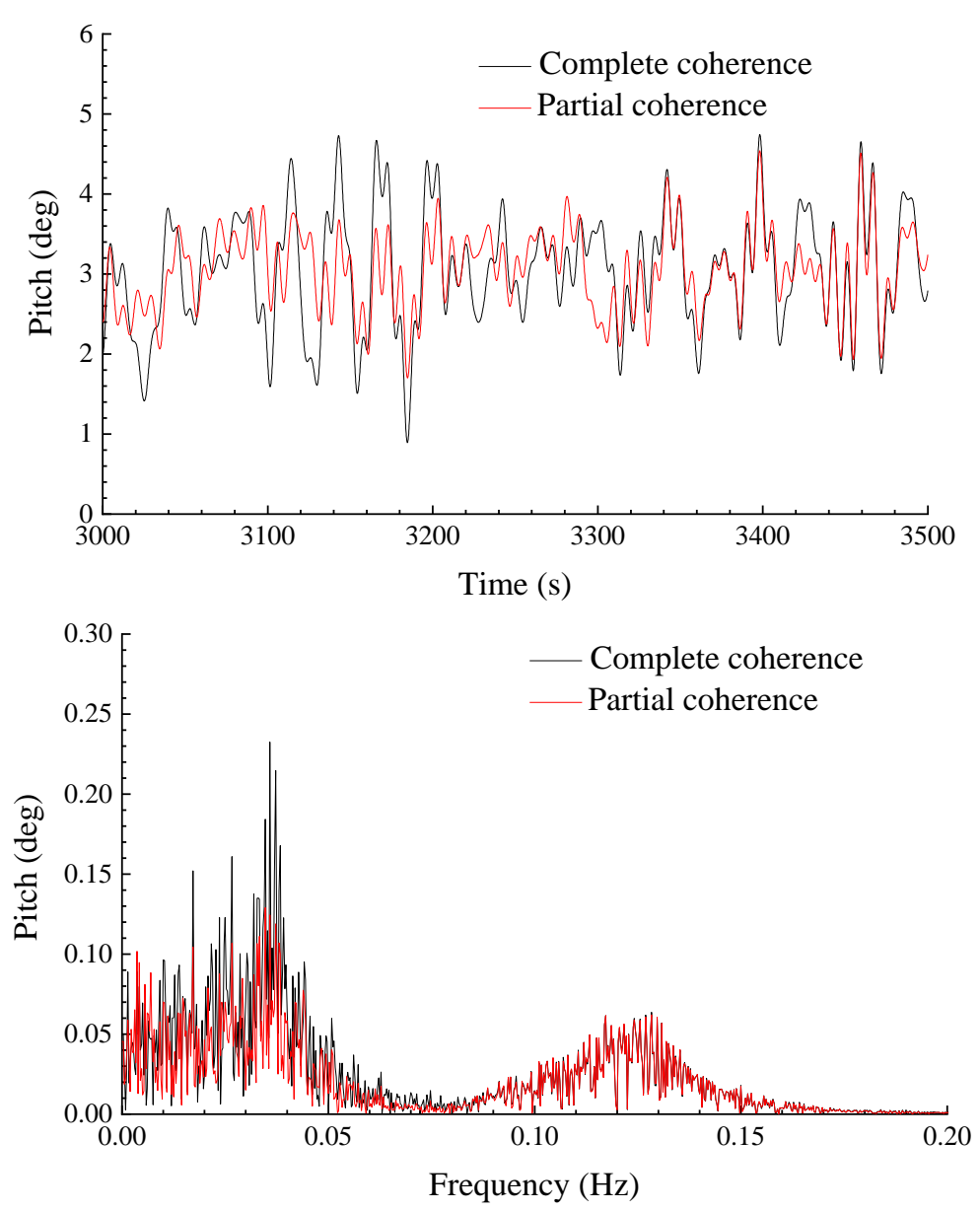

Fig. 22. Platform pitch motion, rated operation condition.

348 At first sight, this conclusion appears contradictory since the spatial inhomogeneity is totally removed when all the points in the wind field are completely coherent. To interpret the underlying

350 philosophy, we plot the average wind speed $\bar{u}=\sum_{i=1}^{N} u_{i} / N$ of the wind grid in Fig. 23 (There are $N=$ 351421 points in the wind field). As shown, when all the points in the wind field are completely coherent, the average wind inflow seems to become more 'turbulent'. In partially coherent wind field (see Fig. 20 , left side), the wind speed at each point oscillates around the mean level of $11.4 \mathrm{~m} / \mathrm{s}$. Due to the phase difference, the instantaneous speeds at some points are higher than $11.4 \mathrm{~m} / \mathrm{s}$ whereas lower than the mean level at others. In this circumstance, the variation of the average wind speed seen by the rotor is relieved due to the phase lag at different points. Consequently, the average wind speed across the rotor plane is close to $11.4 \mathrm{~m} / \mathrm{s}$, although it also varies with time. On the contrary, the wind speeds at all points are in phase with each other if the wind field is completely coherent. If the speed at the reference point (hub centre) exceeds $11.4 \mathrm{~m} / \mathrm{s}$, then the speeds at all other point are higher than 11.4 $\mathrm{m} / \mathrm{s}$ as well. Apparently, the inflow seen by the rotor is more unstable in the presence of complete coherence. The result is that the rotor will be subject to more violent aerodynamic loads. 


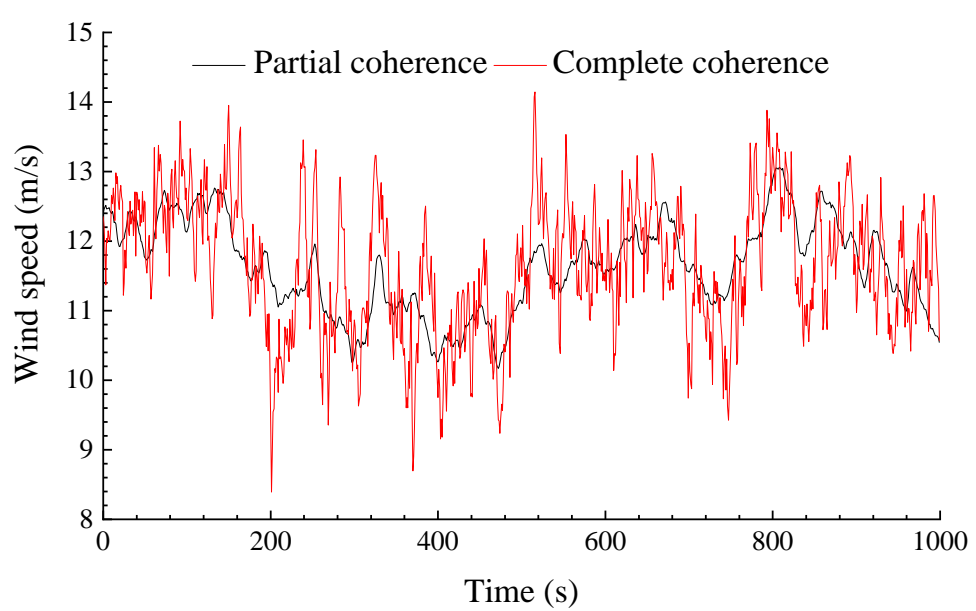

Fig. 23. Average wind speed seen by the rotor, rated operation condition.

\section{Conclusions}

This work aims to investigate how offshore floating wind turbines react to the wind shear, the turbulence intensity and the coherence structure of a turbulent wind field.

The platform is not sensitive to the wind shear since the resultant aerodynamic loads applied on the three blades will not differ much. Nevertheless, the structural load at each individual blade becomes unstable in the wind shear. During the rotation process, a blade experiences low-speed and high-speed regions alternately due to the wind shear. Consequently, load at each blade is excited at the 1P frequency.

The turbulence intensity effect on the floating wind turbine is quite considerable. According to the wind spectrum, the air inflow mainly carries low-frequency components and thereby the low-frequency platform motion responses are excited. Moreover, the response is not sensitive to the turbulence intensity at high frequency range (higher than the resonant frequency). Regarding the structural loads, the floating wind turbine is more likely to exceed the limit state with high turbulence intensity.

The coherence structure of the turbulent wind field is interpreted quantitatively using the proper orthogonal decomposition method. Although a completely coherent wind field removes the spatial inhomogeneity, the time-scale variation increases. In a partially coherent wind field, the average wind inflow seen by the rotor is more stable. Therefore, the floating wind turbine is safer in a partially coherent wind field.

\section{Acknowledgement}

The authors would like to acknowledge China Scholarship Council for the financial support (No. 201506230127). 


\section{References}

Barthelmie, R.J., Frandsen, S.T., Nielsen, M.N., Pryor, S.C., Rethore, P.E., Jorgensen, H.E., 2007. Modelling and measurements of power losses and turbulence intensity in wind turbine wakes at Middelgrunden offshore wind farm. Wind Energy 10 (6), 517-528.

Barthelmie, R.J., Jensen, L.E., 2010. Evaluation of wind farm efficiency and wind turbine wakes at the Nysted offshore wind farm. Wind Energy 13 (6), 573-586.

Chamorro, L.P., Lee, S.J., Olsen, D., Milliren, C., Marr, J., Arndt, R.E.A., Sotiropoulos, F., 2015. Turbulence effects on a full-scale $2.5 \mathrm{MW}$ horizontal-axis wind turbine under neutrally stratified conditions. Wind Energy 18 (2), 339-349.

International Electrotechnical Commission, 2015. IEC 61400-1 Wind turbines part 1, Design requirements.

Coulling, A.J., Goupee, A.J., Robertson, A.N., Jonkman, J.M., Dagher, H.J., 2013. Validation of a FAST semi-submersible floating wind turbine numerical model with DeepCwind test data. Journal of Renewable and Sustainable Energy 5 (2), 023116.

Devinant, P., Laverne, T., Hureau, J., 2002. Experimental study of wind-turbine airfoil aerodynamics in high turbulence. Journal of Wind Engineering and Industrial Aerodynamics 90 (6), 689-707.

Duan, F., Hu, Z.Q., Wang, J., 2016. Investigation of the VIMs of a spar-type FOWT using a model test method. Journal of Renewable and Sustainable Energy 8 (6).

Equinor, 2017a. Hywind - the world's leading floating offshore wind solution, https://www.equinor.com/en/what-we-do/hywind-where-the-wind-takes-us.html.

Equinor, 2017b. World's first floating wind farm has started production, https://www.equinor.com/en/news/worlds-first-floating-wind-farm-started-production.html.

Hu, Z.Q., Li, L., Wang, J., Hu, Q.H., Shen, M.C., 2016. Dynamic responses of a semi-type offshore floating wind turbine during normal state and emergency shutdown. China Ocean Engineering 30 (1), 97-112.

Jonkman, J.M., Buhl Jr, M.L., 2005. FAST User's Guide. National Renewable Energy Laboratory (NREL).

Jonkman, J.M., Butterfield, S., Musial, W., Scott, G., 2009. Definition of a 5-MW reference wind turbine for offshore system development. National Renewable Energy Laboratory Golden, CO.

Lee, K.Y., Tsao, S.H., Tzeng, C.W., Lin, H.J., 2018. Influence of the vertical wind and wind direction on the power output of a small vertical-axis wind turbine installed on the rooftop of a building. Applied Energy 209, 383-391.

Li, L., Cheng, Z., Yuan, Z., Gao, Y., 2018a. Short-term extreme response and fatigue damage of an integrated offshore renewable energy system. Renewable Energy 126, 617-629. 

semisubmersible floating wind turbine with an improved deficient thrust force correction approach. Renewable Energy 119, 95-105.

Li, L., Gao, Y., Yuan, Z.M., Day, S., Hu, Z.Q., 2018c. Dynamic response and power production of a floating integrated wind, wave and tidal energy system. Renewable Energy 116, 412-422.

Li, L., Liu, Y., Yuan, Z., Gao, Y., 2018d. Wind field effect on the power generation and aerodynamic performance of offshore floating wind turbines. Energy 157, 379-390.

Liu, Y.C., Xiao, Q., Incecik, A., Peyrard, C., Wan, D.C., 2017. Establishing a fully coupled CFD analysis tool for floating offshore wind turbines. Renewable Energy 112, 280-301.

Minnema, J.E., 1998. Pitching moment predictions on wind turbine blades using the BeddoesLeishman model for unsteady aerodynamics and dynamic stall. Department of Mechanical Engineering, University of Utah.

Naess, A., Gaidai, O., 2009. Estimation of extreme values from sampled time series. Structural Safety 31 (4), 325-334.

Oguz, E., Clelland, D., Day, A.H., Incecik, A., Lopez, J.A., Sanchez, G., Almeria, G.G., 2018.

434 Experimental and numerical analysis of a TLP floating offshore wind turbine. Ocean Engineering 147, $435 \quad 591-605$.

$436 \quad$ NWTC Information Portal, 2016. TurbSim, https://nwtc.nrel.gov/TurbSim.

437 Robertson, A., Jonkman, J., Masciola, M., Song, H., Goupee, A., Coulling, A., Luan, C., 2014. 438 Definition of the semisubmersible floating system for phase II of OC4. National Renewable Energy 439 Laboratory (NREL), Golden, CO. 